\title{
Clinicopathological and Biochemical Profile of Chronic Kidney Disease of Unknown Aetiology in a Tertiary Care Rural Hospital of Central India
}

\author{
Nakul Kadam ${ }^{1}$, Sourya Acharya ${ }^{2}$, Amol Bawane ${ }^{3}$, Samarth Shukla ${ }^{4}$, Sunil Kumar ${ }^{5}$, Sneha Palaskar ${ }^{6}$ \\ 1,2,5 Department of Medicine, Datta Meghe Institute of Medical Sciences (Deemed to Be University), \\ Sawangi Meghe, Wardha, Maharashtra, India. ${ }^{3}$ Department of Nephrology, Datta Meghe Institute of \\ Medical Sciences (Deemed to Be University), Sawangi Meghe, Wardha, Maharashtra, India. ${ }^{4}$ \\ Department of Pathology, Datta Meghe Institute of Medical Sciences (Deemed to Be University), \\ Sawangi Meghe, Wardha, Maharashtra, India. ${ }^{6}$ Department of Radiology, Datta Meghe Institute of \\ Medical Sciences (Deemed to Be University), Sawangi Meghe, Wardha, Maharashtra, India.
}

\section{ABSTRACT}

\section{BACKGROUND}

Chronic kidney disease (CKD) is a global health problem which is progressive and asymptomatic until the end stage in recent years which is most common in patients of middle and low socio-economic status. The disease is mostly associated with diabetes or hypertension, young and middle-aged individuals living in agricultural communities and drinking well water. We want to study the clinicopathological profile of chronic kidney disease of unknown aetiology (CKDU) cases admitted in a rural tertiary care hospital.

\section{METHODS}

A retrospective study was conducted among fifty patients who reported with ultrasonography (USG) report showing small shrunken kidneys and / or kidney biopsy suggestive of chronic tubulointerstitial nephritis with absence of immune deposits and admitted in the Medicine department of AVBRH Hospital and JNM College of Medical Sciences, Sawangi (M) Wardha of Central India.

\section{RESULTS}

The mean age was $36.46 \pm 10.90$ years with majority of the patients between the ages of 35 to 55 years. The body mass index (BMI) of the study group was within $22.52 \pm$ 1.96. CKDU was more commonly seen in males (64\%) as compared to females (36 $\%)$. The subjects were predominantly farmers (54\%) who used to drink well water. USG showed small shrunken kidneys in all the study subjects, which was in $100 \%$ cases. Pesticide exposure was seen in $32 \%$ cases. The glomerular filtration rate (GFR) revealed that $30 \%$ of the patients were in grade II. The biochemical report revealed the mean value of haemoglobin to be $8.75 \pm 1.39$, mean serum urea level to be 64.96 \pm 15.19 , mean serum creatinine level to be $4.5 \pm 2.67$, mean serum sodium level to be $132.48 \pm 5.83$ and mean serum potassium to be $4.43 \pm 0.78$. The mean random blood sugar (RBS) value was $98.64 \pm 19.62$, serum calcium level was $8.87 \pm 0.43$, serum phosphorus level was $5.05 \pm 0.39$ and urine protein / creatinine ratio was $0.90 \pm 0.12$.

\section{CONCLUSIONS}

This study highlights the need to review health policies and allocates resources for prevention and treatment of CKDU in Central India, Maharashtra.

\section{KEY WORDS}

Chronic Kidney Disease of Unknown Aetiology (CKDU), Hypertension, Diabetes, Shrunken Kidneys
Corresponding Author: Dr. Sourya Acharya, Professor and Head of Department, Department of Medicine, Datta Meghe Institute of Medical Sciences (Deemed to Be University),

Sawangi Meghe, Wardha, Maharashtra, India.

E-mail: souryaacharya74@gmail.com

DOI: $10.14260 / j e m d s / 2021 / 263$

How to Cite This Article:

Kadam N, Acharya S, Bawane A, et al. Clinicopathological and biochemical profile of chronic kidney disease of unknown aetiology (CKDU) in a tertiary care rural hospital of central India. J Evolution Med Dent Sci 2021;10(17):1235-1240, DOI: 10.14260/jemds/2021/263

Submission 15-12-2020,

Peer Review 24-02-2021,

Acceptance 03-03-2021,

Published 26-04-2021.

Copyright (C) 2021 Nakul Kadam et al. This is an open access article distributed under Creative Commons Attribution License [Attribution 4.0 International (CC BY 4.0)] 


\section{BACKGROUND}

The prevalence of chronic kidney disease of unknown aetiology (CKDU) has increased to a great extent in the last decade among the working age population of agricultural communities of tropical or subtropical regions, specifically in central America and Sri Lanka, ${ }^{1-3}$ low-income and middleincome countries (LMICs), including India. ${ }^{4-8}$ India is one of the most diverse nation in the world in terms of ethnicity, climate, dietary habits, socio-economic status, rural and urban diversity and different diseases. Therefore, clinical presentation of CKDU is different in different region. ${ }^{7}$

The understanding of CKDU is hindered due to the lack of a précised definition of the causes that attribute to the disease. In the clinical context, a patient is said to have CKDU after all the known causes of CKD is excluded. Some common clinical characteristics that define CKDU and differentiate it from some of the known causes of CKD are like the disease is seen in young and middle-aged adults, mostly males who are engaged in strenuous work for their livelihood like agriculture and manual labour, patients who have minimal or no proteinuria. CKDU patients are typically non-diabetic and either have normal blood pressure or are only mildly hypertensive. ${ }^{9}$

In India cause of the first reported case of CKD was CKDU in $18 \%$ of the population. ${ }^{7}$ In the study conducted by Jha et al. in 2013 it was reported that the poorest population were at a higher risk for CKD. ${ }^{10}$ There are certain proposed common feature of Chronic kidney disease of unknown aetiology (CKDU) like the disease is mainly manifested in young male farmers belonging to agricultural farming. The term chronic kidney disease of unknown aetiology (CKDu) was first described in El Salvador in 2000 to describe disease predominantly affecting agricultural communities. Therefore, we performed systemic study to identify common exposure and potential risk factors for chronic kidney disease of unknown aetiology in central India. There are various environmental factors also responsible for Chronic kidney disease of unknown aetiology mainly heavy metal exposures, high seasonal temperatures, agrochemical use, mycotoxins, contaminated water supplies and snake bite. ${ }^{11}$ CKDU is a disease with slow progression, starting in the second decade of life, and asymptomatic until late stage. Peripheral oedema and hypertension are the late presenting features. The main histopathological features are tubular atrophy, interstitial mononuclear cell infiltration and interstitial fibrosis. These histological features suggest that nephrotoxins play a key role in the CKDu. ${ }^{3}$

CKDU is being reported with increasing frequency across the globe and is reported in epidemic proportions. ${ }^{2,12,13}$ Chronic kidney disease (CKD) is a global problem which exhausts healthcare systems and leading to millions of deaths, years of life lost and years lived with disability. The reason for this increasing burden of chronic kidney disease (CKD) is that population in rural areas generally have lesser access to healthcare and incomplete understanding of pathogenesis of CKD. Chronic kidney disease hot spot can be helpful to understand the pathogenesis of kidney disease and to improve the life expectancy of the affected community. CKD hot spot is defined as country, region, and community with greater than average incidence of chronic kidney disease (CKD) compared to worldwide, country or regional rates. ${ }^{13}$
$\mathrm{CKDu}$ is increasingly being recognised in various places in India and hence this disease is required vivid systemic studies and large-scale epidemiologic studies for elucidation of a clear pathognomonic mechanism.

\section{METHODS}

A retrospective study data retrieved from clinical case records, was carried out on patients who reported with renal disorder in the medicine department of AVBRH Hospital and JNM College of Medical Sciences, Sawangi (M) Wardha for a period of 1 year from October 2019 to September 2020. Data were collected retrospectively from hospital records. Out of 355 CKD patients admitted within this period 50 CKDU patients were included in the study. All these 50 patients fulfilled the inclusion criteria i.e. the definition of CKDU. The demographic, clinical data and educational qualification was recorded and informed consent was obtained from the patient. Further parameters were recorded like height, weight family history. Proper medical history was obtained from patient. The biochemical profile was analysed were the glomerular filtration rate (GFR) using CKD EPI (Chronic Kidney Disease Epidemiology Collaboration equation). ${ }^{3}$ Haemoglobin, serum urea, serum creatinine, serum sodium and potassium, serum calcium and phosphorus and RBS were also evaluated for individual patients admitted in the ward. Urine analysis, kidney biopsy, USG of the kidney was further performed. History of pesticide exposer and NSAID abuse was obtained. Symptoms of the patient were recorded along with the neurological manifestations. There is a proposed case definition for Chronic kidney disease of uncertain aetiology in India which is described as. ${ }^{14}$

\section{Criteria for a Suspected Case \\ Mandatory Criteria}

eGFR less than $60 \mathrm{~mL} / \mathrm{min} / 1.73 \mathrm{~m}^{2}$ by CKD-EPI formula and / or urine protein 1 plus or more by dipstick.

\section{Exclusion Criteria}

History of diabetes mellitus or history of anti-diabetic medications / newly detected diabetes as defined by RBS > $200 \mathrm{mg} / \mathrm{dL}^{*}$ Self-reported history of renal disease of known aetiology such as polycystic kidney disease, renal stones, history suggestive of chronic glomerulonephritis, and congenital kidney disease

\section{Criteria for a Possible Case \\ Mandatory criteria}

Estimated GFR (eGFR) less than $60 \mathrm{~mL} / \mathrm{min} / 1.73 \mathrm{~m} 2$ by CKD-EPI formula and / or dipstick urine protein 1 plus or more persisting for more than 3 months (requires repeat testing after 3 months).

\section{Exclusion Criteria}

Diabetes mellitus diagnosed by HbA1c $>6.5 \%$ and FBS $>126$ $\mathrm{mg} / \mathrm{dL}$ or patients on anti-diabetic medications*. Any BP more than 140 / 90 in stage 1, 2 of CKD and BP > 160 / 100 in stage $3,4,5$ of CKD or patients requiring two or more types of antihypertensive medications for BP control. CKD documented 
by ultrasound examination / tests to be suggestive of renal disease of known cause (such as obstructive pathology, stones, vasculitis, lupus).

Urine protein creatinine ratio $>2 \mathrm{~g} / \mathrm{g}$

Haematuria $>5$ red blood cells $/ \mathrm{hpf}$

\section{Criteria for a Definite Case}

All criteria satisfying probable case with USG showing small shrunken kidneys and / or kidney biopsy s / o chronic tubulointerstitial nephritis with absence of immune deposits. ${ }^{14}$

The study was conducted according to the Helsinki Declaration and informed consent was obtained from all the participants. The study was ethically approved by Institutional Ethics Committee, DMIMS, Wardha, India.

\section{Statistical Analysis}

Descriptive statistics was used using SPSS version 25. Data was expressed using frequency, percentage, means \pm standard deviation (S.D)

\section{RESULTS}

The mean age group was $36.46 \pm 10.90$ years with majority of the patients between the age group of 35 to 55 years. The BMI of the study group was within $22.52 \pm 1.96$. CKDU was more commonly seen in males as compared to females. The subjects were predominantly farmers (54\%), $4 \%$ of the study group belonged to drivers, $6 \%$ were teachers, $4 \%$ house wives and remaining $4 \%$ were unemployed. It was studied that $64 \%$ of the study population used to have mixed diet. $54 \%$ used to drink well water, $20 \%$ river water and $18 \%$ bore well water and the rest, that is $8 \%$ used to drink pond water. In our study $64 \%$ of the subjects included were educated. (Table 1)

\begin{tabular}{|cccccc|}
\hline & Range & Minimum Maximum & Mean & $\begin{array}{c}\text { Std. } \\
\text { Deviation }\end{array}$ \\
Age & 35.00 & 20.00 & 55.00 & 36.4600 & 10.90443 \\
BMI & 9.60 & 19.00 & 28.60 & 22.5200 & 1.96490 \\
\hline \multicolumn{5}{|c}{ Table 1. Baseline Characteristics of Cases } \\
\hline
\end{tabular}

In future history taking there were only $12 \%$ cases that had a significant family history and detected hypertension was detected in $10 \%$ cases. Rest $90 \%$ had no history. Habit history revealed that there was no habit history in $64 \%$ cases, smoking in $2 \%$, chewing tobacco in $12 \%$ cases, alcoholic in 24 $\%$ and smoking tobacco and alcoholic in $12 \%$ cases. (Table 2)

The GFR rate revealed $30 \%$ of the patients in grade II, 12 $\%$ grade IIIB, $8 \%$ grade IIIA, $22 \%$ grade IV and $28 \%$ grade $\mathrm{V}$. kidney biopsy was not done in $94 \%$ cases and in $6 \%$ cases it revealed chronic tubulo-nephritis with absence of immune deposit. USG showed small shrunken kidney in all the study subjects, which is in $100 \%$ cases. Pesticide exposure was seen in $32 \%$ cases and $68 \%$ had no pesticide exposure. At the time of presentation, symptoms observed were, loss of appetite, nausea, vomiting was seen in $20 \%$ of the cases included in the study, $30 \%$ had swelling of arm and legs, $12 \%$ had muscle cramp, dry skin, nausea, $10 \%$ had difficulty in breathing, lethargy, diarrhoea, vomiting in $10 \%$ of patients and nausea, vomiting, itching, bone and joint pain in $8 \%$ of the cases and $10 \%$ were asymptomatic. The neurological manifestations were peripheral neuropathy in $18 \%$ cases, encephalopathy in $2 \%$ cases, autonomic dysfunction in $8 \%$ cases and no symptoms in $72 \%$ cases. NSAID'S abuse was prominent in 20 $\%$ cases and not seen in $80 \%$ cases. (Table 3 )

\begin{tabular}{|c|c|c|c|}
\hline & & Frequency & Percent \\
\hline \multirow{2}{*}{ Gender } & Male & 32 & 64.0 \\
\hline & Female & 18 & 36.0 \\
\hline \multirow{6}{*}{ Occupation } & Farmer & 27 & 54.0 \\
\hline & Labourer & 14 & 28.0 \\
\hline & Driver & 2 & 4.0 \\
\hline & Teacher & 3 & 6.0 \\
\hline & Housewife & 2 & 4.0 \\
\hline & Unemployed & 2 & 4.0 \\
\hline \multirow{2}{*}{ Food Habit } & Veg & 18 & 36.0 \\
\hline & Mixed & 32 & 64.0 \\
\hline \multirow{4}{*}{ Source of drinking water } & River & 10 & 20.0 \\
\hline & Well water & 27 & 54.0 \\
\hline & Bore well & 9 & 18.0 \\
\hline & Pond & 4 & 8.0 \\
\hline \multirow{2}{*}{ Education } & Yes & 32 & 64.0 \\
\hline & No & 18 & 36.0 \\
\hline \multirow[b]{2}{*}{ Family history } & Significant & 6 & 12.0 \\
\hline & Not Significant & 44 & 88.0 \\
\hline \multirow{3}{*}{ History of DM HTN } & No history & 45 & 90.0 \\
\hline & Hypertension & 5 & 10.0 \\
\hline & Diabetes Mellitus & 0 & 0.0 \\
\hline \multirow{5}{*}{ Habit history } & No & 32 & 64.0 \\
\hline & Smoker alcoholic & 6 & 12.0 \\
\hline & Alcoholic & 12 & 24.0 \\
\hline & Tobacco chewing & 6 & 12.0 \\
\hline & Smoker & 1 & 2.0 \\
\hline Table 2. De & nographic Char & teristics of $C$ & \\
\hline
\end{tabular}

\begin{tabular}{|c|c|c|c|}
\hline \multicolumn{2}{|c|}{ Clinical and Biochemical Variables } & \multicolumn{2}{|c|}{ FrequencyPercen } \\
\hline \multirow{5}{*}{ GFR } & $60-89($ stage ii) & 15 & 30.0 \\
\hline & $30-43$ (stage iii b) & 6 & 12.0 \\
\hline & $44-59$ (stage iii a) & 4 & 8.0 \\
\hline & $15-29$ (stage iv) & 11 & 22.0 \\
\hline & $<15$ (stage v) & 14 & 28.0 \\
\hline \multirow[b]{2}{*}{ Kidney biopsy } & Not done & 47 & 94.0 \\
\hline & $\begin{array}{l}\text { s / o chronic tubulo-nephritis with } \\
\text { absence of immune deposit }\end{array}$ & 3 & 6.0 \\
\hline USG & $\begin{array}{c}\text { USG showing small shrunken } \\
\text { kidney }\end{array}$ & 50 & 100.0 \\
\hline \multirow{2}{*}{ Pesticide exposure } & Yes & 16 & 32.0 \\
\hline & No & 34 & 68.0 \\
\hline \multirow{7}{*}{$\begin{array}{l}\text { Symptoms with } \\
\text { duration }\end{array}$} & Loss of appetite, nausea, vomiting & 10 & 20.0 \\
\hline & Swelling of arm and legs & 15 & 30.0 \\
\hline & Muscle cramp, dry skin, nausea & 6 & 12.0 \\
\hline & Difficulty in breathing & 5 & 10.0 \\
\hline & Lethargy, diarrhoea, vomiting & 5 & 10.0 \\
\hline & $\begin{array}{c}\text { Nausea, vomiting, itching, bone and } \\
\text { joint pain }\end{array}$ & 4 & 8.0 \\
\hline & Asymptomatic & 5 & 10.0 \\
\hline \multirow{4}{*}{$\begin{array}{l}\text { Neurological } \\
\text { manifestations }\end{array}$} & Peripheral neuropathy & 9 & 18.0 \\
\hline & Encephalopathy & 1 & 2.0 \\
\hline & Autonomic dysfunction & 4 & 8.0 \\
\hline & No symptoms & 36 & 72 \\
\hline \multirow{2}{*}{ NSAIDs abuse } & Yes & 10 & 20.0 \\
\hline & No & 40 & 80.0 \\
\hline \multicolumn{4}{|c|}{ Table 3. GFR, Aetiologic Factors, and Clinical Features } \\
\hline
\end{tabular}

The biochemical report revealed the mean value of haemoglobin was $8.75 \pm 1.39$, mean serum Urea level $64.96 \pm$ 15.19 , mean serum creatinine level $4.5 \pm 2.67$, mean serum sodium level $132.48 \pm 5.83$, mean serum potassium $4.43 \pm$ 0.78 . The mean rbs value $98.64 \pm 19.62$, serum calcium level 
$8.87 \pm 0.43$, serum phosphorus level $5.05 \pm 0.39$ and urine protein / creatinine ratio $0.90 \pm 0.12$. (Table 4)

\begin{tabular}{|c|c|c|c|c|}
\hline $\begin{array}{l}\text { Biochemical } \\
\text { Parameters }\end{array}$ & Minimum & Maximum & Mean & Std. Deviation \\
\hline HB & 4.60 & 12.00 & 8.7580 & 1.39797 \\
\hline SR urea & 38.00 & 90.00 & 64.9660 & 15.19806 \\
\hline SR creatinine & 1.8 & 18.80 & 4.5680 & 2.67799 \\
\hline SR sodium & 114.00 & 146.00 & 132.4800 & 5.83879 \\
\hline SR potassium & 2.40 & 5.70 & 4.4300 & .78148 \\
\hline RBS & 60.00 & 180.00 & 98.6400 & 19.62169 \\
\hline SR calcium & 8.00 & 9.60 & 8.8760 & .43310 \\
\hline SR phosphorus & 4.00 & 6.00 & 5.0500 & .39808 \\
\hline $\begin{array}{l}\text { Urine protein / } \\
\text { creatinine ratio }\end{array}$ & 0.4 & 1.59 & 0.900 & .123 \\
\hline \multicolumn{5}{|c|}{ Table 4. Kidney Function Tests, Proteinuria } \\
\hline
\end{tabular}

\section{DISCUSSION}

Vidharbha is a geographically located in the state Maharashtra with a geographical area of 6310 square $\mathrm{km}$ and a total population of 585 people among which 295 are males and 290 females according to census 2011. $24.59 \%$ of the total workers are engaged as cultivators and $54.55 \%$ of the total workers are engaged as agricultural labourers in the region. Together it constitutes $79.14 \%$ of the total workers of the Vidharbha region. The principal crops grown are wheat, jowar, cotton, pulses. ${ }^{15}$

The age group in our study was $36.4 \pm 10.90$ years which was in accordance with the findings of Uddanam study where mean age of the subjects was $43.2 \pm 14.2$ years. ${ }^{16}$ A study was conducted by O'Callaghan-Gordo C et al. where the BMI was 24 $\pm 5.0 \mathrm{~kg} / \mathrm{m}^{2}$ which was in accordance with our study where the BMI in our study was $22.52 \pm 1.96 \mathrm{~kg} / \mathrm{m}^{2}, 17$

A study had been conducted by Ookalkar D et al. in 2020 where he found that CKDu was predominant in males because mostly agricultural labourers and farmers were around 78.94 $\% .{ }^{18}$ Similar results were also found in our study where the males had a predominance by $64 \%$.

Agriculture is an area dependent element based on various factors like the soil, climate, and irrigational factors. Vidharba having a very hot, dry and sub-humid climate, the summers are too dry and the winter stays for a shorter period and is very mild. The most common occupation being farming and so dehydration has been a very common phenomenon. ${ }^{19-21}$ In our study $54 \%$ of the study population had well water which was also in accordance with the study at Yavatmal where the subject population had well water as the source of drinking water $(100 \%) .{ }^{17} 64 \%$ of the study population in our study was educated which was in accordance with the study conducted by Tatapudi RR et al. which was $57.7 \% .16$

Since farmers are exposed to extreme heat and due to very hot climate in Vidharba, they have excessive sweating and they are not able to input necessary amount of water leading to repeated dehydration. Hard working population must be made aware of the importance of frequent hydration while working in such climatic conditions. There have been studies which have shown that young males who are hard working in such dry climates were predominantly affected on endemic nephropathy around the world. ${ }^{20}$

Habit history revealed in our study that $24 \%$ of them had habit of Alcohol and $12 \%$ had a habit of tobacco chewing. This was not in accordance with the study conducted by Callaghan
Gordo C in 2019 where he reported that $19 \%$ of them had habit of alcohol and $25 \%$ tobacco consumption. ${ }^{23}$

The mean GFR (stage II) in our study was seen in $30 \%$ which was 60 - $89 \mathrm{~mL} / \mathrm{min}$, stage IIIB $12 \%$ which was $30-$ $43 \mathrm{~mL} / \mathrm{min}$, stage IIIA $8 \%$ which was $44-59 \mathrm{~mL} / \mathrm{min}$, stage IV that is $22 \%$ and in a range of $15-29 \mathrm{~mL} / \mathrm{min}$ and stage $\mathrm{V}$ is $28 \%$ which is $<15 \mathrm{~mL} / \mathrm{min}$. According to the study conducted by O'Callaghan-GordoCet et al., the authors observed differences in mean eGFR depending on the geographic area in India where $104.5 \pm 17.6$ in urban areas of Northern India, $100.3 \pm 16.2$ in rural areas of Northern India, $110.9 \pm 15.7$ in urban areas of Southern India and $97.4 \pm 19.8$ in the rural area of Southern India.

In our study there was no significant family history of CKDU. In our study newly detected hypertensive cases was 10 $\%$ and diabetes mellitus was $0 \%$ cases which was not in accordance with the study conducted at Yavatmal where only five of the 19 patients had hypertension, and were on antihypertensive medications. ${ }^{18}$ A study conducted by RR Tatapudiet al. in Uddanam city had similar results as our study which revealed there were $85.1 \%$ hypertensive patients where $14.9 \%$ were discovered to be hypertensive during the study time. Diabetes was found in $7.2 \%$ cases. $^{16}$

Renal biopsy is normally done to reveal the anatomic aetiology of CKDU. In our study, biopsy revealed tubulonephritis with absence of immune deposit. There have been studies conducted where renal biopsy revealed Foci of tubular atrophy and interstitial fibrosis (40\%) were seen. Widespread flattening and loss of brush border of proximal tubules were noted. The interstitium showed diffuse mononuclear cell inflammatory infiltrate with few eosinophils. ${ }^{17}$ Similar reports also revealed foci of tubular atrophy and interstitial fibrosis in 2015.21 USG shows small shrunken kidneys in our study in 100 $\%$ cases in our study. In our study $32 \%$ of the affected study population has been exposed to pesticides as maximum study population belonged to farmers by occupation. Similar results have also been revealed in other studies. ${ }^{16,18}$ In our study the NSAID abuse has also been rarely seen which has accounted for only $20 \%$.

In our study the clinical symptoms observed were that 20 $\%$ of the patients presented with loss of appetite, nausea, vomiting, $30 \%$ suffered from swelling of arm and legs, $12 \%$ from muscle cramp, dry skin, nausea, $20 \%$ difficulty in breathing, $10 \%$ lethargy, diarrhoea, vomiting and $8 \%$ nausea, vomiting, itching, bone and joint pain and asymptomatic $10 \%$. Johnson RJ et al. reviewed an article in 2019 where he described that in Mesoamerican Nephropathy the common clinical features were Fever, elevated serum creatinine level, muscle and joint pain, leucocytosis, leukocyturia, haematuria in acute phase. In Sri Lankan Nephropathy the features were Fever, fatigue, dysuria, and joint pain in acute phase. ${ }^{23}$

According to our study the neurological manifestations observed were that $18 \%$ had peripheral neuropathy, $2 \%$ Encephalopathy, $8 \%$ autonomic dysfunction and $72 \%$ had no symptoms. Krishnan AV \& Kiernan MC in 2009 conducted a review where they expressed that Peripheral neuropathy was a common manifestation in almost all the patients, leading to weakness and disability. There were other features like chronic cognitive impairment and dementia, myopathy, carpal tunnel syndrome and stroke. ${ }^{24}$

In the study conducted at Yavatmal in 2020 the mean haemoglobin was $11.04 \pm 1.75 \mathrm{gm} / \mathrm{dL}$ which was not in 
accordance to our study which was $8.75 \pm 1.39 \mathrm{mg} / \mathrm{dL}$. In our study the mean serum urea level was $64.96 \pm 15.19 \mathrm{mg} / \mathrm{dL}$ which was similar to other studies.17,22 According to Ookalkar D et al. the mean serum creatinine was $3.8 \pm 2.4 \mathrm{mg} / \mathrm{dL}$ which was in accordance with our study which was $4.56 \pm 2.67$. Mean Serum sodium level in our study was $132.48 \pm 5.83 \mathrm{mEq} / \mathrm{L}$ and the mean potassium sodium level $4.43 \pm 0.78 \mathrm{mEq} / \mathrm{L}$. this was similar to the study conducted by Ookalkar D et al. where mean serum sodium level was $135.48 \pm 3.33 \mathrm{mEq} / \mathrm{L}$ and the mean potassium sodium level was $4.6 \pm 0.7 \mathrm{mEq} / \mathrm{L} .{ }^{16}$ In our study the mean RBS was $98.64 \pm 19.62$, the mean serum calcium level was $8.87 \pm 0.433$ and serum phosphorus $5.05 \pm$ 0.39 .

Studies have shown that the patients suffering from CKDU in Central America had varying degrees of proteinuria which was measured by the urine protein creatinine ratio. The majority had proteinuria less than 1 gm per day where results revealed that there was little or no proteinuria. ${ }^{19}$ This was similar to our study which revealed $0.900 \pm 0.12$. This was also similar to the study conducted at Yavatmal where urine protein creatinine ratio was $0.93 \pm 0.35 .17$

This is a case series reported from Vidharbha region, Wardha District where 50 admitted patients were included in the study and patients were mostly farmers. A spate of this disease is occurring at an exponential rate at several regions of the world, affecting manual workers who are hard working in hot, agricultural communities. The aetiology is unknown but may involve a complex interplay of environmental exposures, infections, genetic factors, and heat. Preventive measures have included programs to ensure safe drinking water, adequate hydration, rest, and shade for workers at risk, as well as to reduce exposure to pesticides.

\section{CONCLUSIONS}

CKDU is increasingly being recognized in certain geographic areas in India which requires large-scale epidemiologic studies and systematic reviews for elucidation of a clear pathogenetic mechanism. CKDU has resulted in considerable morbidity and mortality among the agricultural community. Due to extreme dry and hot climate, dehydration has been a common problem and patients who were mostly farmers, drank water from well. There have been many patients who have died because of unknown aetiology and hence CKDU needs more intense study for people's welfare in Vidharba region.

Data sharing statement provided by the authors is available with the full text of this article at jemds.com.

Financial or other competing interests: None.

Disclosure forms provided by the authors are available with the full text of this article at jemds.com.

\section{REFERENCES}

[1] Wesseling C, Crowe J, Hogstedt C, et al. Mesoamerican nephropathy: report from the first International Research Workshop on men. Universidad Nacional Costa Rica 2013.

[2] Correa-Rotter R, Wesseling C, Johnson RJ. CKD of unknown origin in Central America: the case for a mesoamerican nephropathy. Am J Kidney Dis 2014;63(3):506-20.

[3] Jayatilake N, Mendis S, Maheepala P, et al. Chronic kidney disease of uncertain aetiology: prevalence and causative factors in a developing country. BMC Nephrol 2013;14:180.

[4] Seck SM, Doupa D, Gueye L, et al. Prevalence of chronic kidney disease and associated factors in senegalese populations: a community-based study in saint-louis. Nephrourol Mon 2014;6(5):e19085.

[5] Barsoum RS. Burden of chronic kidney disease: North Africa. Kidney Int Suppl (2011) 2013;3(2):164-6.

[6] El Minshawy O, Ghabrah T, El Bassuoni E. End-stage renal disease in Tabuk Area, Saudi Arabia: an epidemiological study. Saudi J Kidney Dis Transpl 2014;25(1):192-5.

[7] Rajapurkar MM, John GT, Kirpalani AL, et al. What do we know about chronic kidney disease in India? First report of the Indian CKD registry. BMC Nephrol 2012;13:10.

[8] Reddy DV, Gunasekar A. Chronic kidney disease in two coastal districts of Andhra Pradesh, India: role of drinking water. Environ Geochem Health 2013;35(4):439-54.

[9] Rajapakse S, Shivanthan MC, Selvarajah M. Chronic kidney disease of unknown aetiology (CKDu) in Shrilanka. Int J Occuo Environ Health 2016:22(3):259-64.

[10] Jha V, Garcia-Garcia G, Iseki K, et al. Chronic kidney disease: global dimension and perspectives. Lancet 2013;382(9888):260-72.

[11] Lunyera J, Mohottige D, Isenburg MV, et al. CKD of uncertain etiology: a systematic review. Clin J Am Soc Nephrol 2016;11(3):379-85.

[12] Orantes CM, Herrera R, Almaguer M, et al. Chronic kidney disease and associated risk factors in the BajoLempa region of El Salvador: nefrolempa study 2009. MEDICC Rev 2011;13(4):14-22.

[13] Martin-Cleary C, Ortiz A. CKD hotspots around the world: Where, why and what the lessons are. A CKJ review series. Clin Kidney J 2014;7(6):519-23.

[14] Anupama YJ, Sankarasubbaiyan S, Taduri G. Chronic kidney disease of unknown etiology: case definition forindia-a perspective. Indian J Nephrol 2020;30(4):23640.

[15] District Census Handbook (DCHB) 2011. GOI 2011. https://censusindia.gov.in/2011census/dchb/DCHB.ht ml. Retrieved 08 August 2019.

[16] Tatapudi RR, Rentala S, Gullipalli P, et al. High prevalence of CKD of unknown etiology in Uddanam, India. Kidney Int Rep 2018;4(3):380-9.

[17] O'Callaghan-Gordo C, Shivashankar R, Anand S, et al. Prevalence of and risk factors for chronic kidney disease of unknown aetiology in India: secondary data analysis of three population-based crosssectional studies. BMJ Open 2019;9(3):e023353.

[18] Ookalkar D, Ookalkar A, Gupta VL, et al. Clinical profile of chronic kidney disease of unknown origin in patients of Yavatmal district, Maharashtra, India. J Renal Endocrinol 2020;7:e01.

[19] Designing rural technology delivery system for mitigating agricultural distress: a study of Wardha district. Chennai: MS Swaminathan Reseach Foundation 2009.

[20] Gifford FJ, Gifford RM, Eddleston M, et al. Endemic nephropathy around the world. Kidney Int Rep 2017;2(2):282-92. 
[21] Almaguer M, Herrera R, Orantes CM. Chronic kidney disease of unknown etiology in agricultural communities. MEDICC Rev 2014;16(2):9-15.

[22] Weaver VM, Fadrowski JJ, Jaar BG. Global dimensions of chronic kidney disease of unknown etiology (CKDu): a modern era environmental and/or occupational nephropathy? BMC Nephrol 2015;16:145.
[23] Johnson RJ, Wesseling C, Newman LS. Chronic kidney disease of unknown causein agricultural communities. N Engl J Med 2019;380(19):1843-52.

[24] Krishnan AV, Kiernan MC. Neurological complications of chronic kidney disease. Nat Rev Neurol 2009;5(10):54251. 